\title{
Experience of using sewage sludge in soil for green building
}

\author{
Irina Elshaeva ${ }^{2}$, Vera Titova $^{1}$, Alexander Vetchinnikov ${ }^{1}$, Anna Pinaeva $^{2}$, and Oksana \\ Vetchinnikova $^{1}$ \\ ${ }^{1}$ Nizhny Novgorod State Agricultural Academy, Gagarina, 97, 603107 Nizhny Novgorod, Russian \\ Federation \\ ${ }^{2}$ Saint-Petersburg State Agrarian University, Petersburgskoe shosse, 2, 196601 Pushkin, Saint- \\ Petersburg, Russian Federation
}

\begin{abstract}
Wastewater sludge from municipal wastewater treatment plants in Nizhny Novgorod and soils based on them, prepared with different ratios of sludge, sawdust and peat, have been investigated. Sewage sludgebased soils contain plant nutrients and are suitable for use as fertilizing materials in green building. Under the conditions of a three-year lysimetric experiment on cereal lawn grasses, a significant efficiency of organic soils was noted in comparison with traditional soils. The lawn maintenance regime revealed differences in the mixtures of fertilizing materials in terms of the effect on the productivity of the phytocenosis. Use of sewage sludge containing large amounts of heavy metals as one of the soil components undoubtedly leads to increase in the amount of these toxic elements in the soil as a whole.
\end{abstract}

\section{Introduction}

Analysis of the environmental situation in the production area of the Nonchernozem belt shows that the main reason for the negative impact on the environment of industrial and municipal enterprises is the low efficiency of waste management. Wherein, being a rich source of organic material, energy and macronutrients, they can be used to solve a wide variety of environmental and economic problems $[1,2]$. The studies carried out to assess some industrial wastes containing calcium indicate the possibility of their use as ameliorants on acidic soddy-podzolic and podzolic soils $[3,4,5]$.

Along with traditional organic fertilizers in modern agriculture, alternative fertilizing materials are also involved in operation with strict adherence to scientific recommendations for use. The degree of influence of organic waste on the agrochemical properties of the soil depends on the application dose, culture and duration of application. The batteries in them are in organic form, which reliably prevents them from being washed out and promotes prolonged action. In general, they provide a positive balance of nitrogen, phosphorus and potassium in the soil, increase enzymatic activity, the total number of microorganisms and soil respiration $[4,5,6]$.

Study in the field of environmental assessment and wastewater sludge disposal technology (WWS) has been going on since the 80s of the twentieth century [7]. Recommendations have been developed and limits have been determined for introduction 
of waste silts into the soil for agricultural industrial crops. It is noted that sewage sludge has a noticeable direct and long-term aftereffect $[7,8]$. The effect of direct action is all the more pronounced on impoverished soils. In some cases, the aftereffect of sediment is long-term and ultimately contributes to the long-term preservation of soil fertility.

The issues of using organic waste as a secondary material resource are becoming increasingly important as the modern housing complex and green building facilities develop. Waste silt finds its way into the regeneration of urban landscapes and land reclamation, making its utilization of environmentally and economically sound [9-15].

The purpose of the paper is to study the possibility of using sewage sludge from sewage treatment plants of public utilities in the city of Nizhny Novgorod and composts based on them in green construction and for the creation of cereal grass.

Study objectives: to determine the agrochemical and toxicological indicators of sewage sludge and soils based on them. To assess the possibility of using sediments and composts as unconventional organic fertilizers in urban soils. To study the effectiveness of WWS and composts and their effect on development of lawn grasses under the conditions of vegetation lysimetric experiments.

\section{Materials and Methods}

The objects of study were the waste silts of the Nizhny Novgorod aeration station and soils prepared on their basis: with soil, peat and sawdust in various ratios. As a control option, a standard soil was used, consisting of $60 \%$ peat, $20 \%$ soil, and $10 \%$ manure and sand. The experiment scheme consisted of five options:

1. Standard soil

2. WWS: sawdust: peat $-0.5: 1: 1$

3. WWS: sawdust: peat $-0.5: 2: 1$

4. WWS: sawdust: peat $-0.5: 1: 2$

5. WWS: sawdust: peat - 1: 1: 1

The studies were carried out under the conditions of a vegetation-lysimetric experiment in vessels $70 \mathrm{~cm}$ high and $80 \mathrm{~cm}$ in diameter. The area of each vessel is $0.5 \mathrm{~m}^{2}$. The vessels were located at a distance of $50 \mathrm{~cm}$ from each other, so that their edges were $5 \mathrm{~cm}$ above the soil level and filled with prepared soil. The experiment was repeated three times. The effectiveness of fertilizing materials was studied in many years of experience on a culture traditionally used to create lawns for various purposes.

Meadow fescue (Festuca pratensis) is a perennial cereal plant, which is characterized by early and abundant bushing out, long-term preservation of the ability to shoot. Under certain conditions of agricultural technology, grasses form a dense turf cover and a uniform density of herbage, which exhibits high resistance with systematic mowing. The projective cover is $50-60 \%$. They tolerate unfavorable meteorological conditions and soil salinization.

The experiment provided for the study of two possible methods of using the lawn - with harvesting the mowed mass from the territory of the lawn and leaving it (mowed chopped grass) on the soil surface. Therefore, the lysimeters were divided into two separate parts.

Therefore, in one part of the vessel (series "a"), finely chopped cut grass was left on the surface, that is, the biomass returned to the "soil-plant" system, and in the other part (series "b"), it was alienated from the system and transported for its limits.

The characteristics of the components used for preparation of soils are shown in Table 1. 
Table 1. Initial characteristics of soil components

\begin{tabular}{|c|c|c|c|c|c|c|c|c|}
\hline \multirow[t]{2}{*}{$\begin{array}{c}\text { Component } \\
\mathrm{s}\end{array}$} & \multirow{2}{*}{$\begin{array}{c}\text { Organic } \\
\text { matter, } \\
\%\end{array}$} & \multicolumn{3}{|c|}{$\begin{array}{l}\text { Content of nutrients, \% } \\
\text { on dry matter }\end{array}$} & \multicolumn{4}{|c|}{$\begin{array}{l}\text { The gross content of heavy metals in } \\
\text { the original substrates taken for } \\
\text { preparation of soils, } \mathrm{mg} / \mathrm{kg}\end{array}$} \\
\hline & & $\mathbf{N}$ & $\mathbf{P}_{2} \mathbf{O}_{5}$ & $\mathbf{K}_{2} \mathrm{O}$ & Cd & $\mathbf{P b}$ & $\mathrm{Cu}$ & $\mathrm{Zn}$ \\
\hline WWS & 228 & 2,65 & 7.00 & 0.32 & $\frac{7.0^{1}}{15.0}$ & $\frac{31.0}{250.0}$ & $\frac{205.0}{705.0}$ & $\frac{553.0}{1750.0}$ \\
\hline Sawdust & 31 & 2.24 & 0.09 & 0.16 & 5.0 & 85.0 & 276.0 & 720.0 \\
\hline Peat & 32 & 1.84 & 0.16 & 0.24 & $\frac{1.6^{2}}{2.0}$ & $\frac{18.0}{32.0}$ & $\frac{13.0}{132.0}$ & $\frac{71.0}{220.0}$ \\
\hline $\begin{array}{c}\text { Standard } \\
\text { Soil } \\
\end{array}$ & 24 & $108^{3}$ & $42^{3}$ & $180^{3}$ & $\frac{0.9^{2}}{2.0}$ & $\frac{11.0}{32.0}$ & $\frac{29.0}{132.0}$ & $\frac{61.0}{220.0}$ \\
\hline
\end{tabular}

${ }^{1}$ Above the line there is the total content of HM in the substrate, below the line - MPC according to GOST R 54651-2011 [16]

${ }^{2}$ Above the line there is the total content of HM in the substrate, below the line - MPC (APC)

3 according to SanPiN 2.1.7.573-96 [17]

\section{Results and discussion}

Lawn grasses in multi-cut cultivation consume a large amount of nutrients, especially nitrogen and potassium. During the growing season, sod grasses carry $4.5 \%$ nitrogen, $3 \%$ potassium and $0.7 \%$ phosphorus. The total nitrogen content in WWS is at the level of 2.65 $\%$, while most of it is in a form inaccessible to plants. Presence of a significant amount of phosphorus $(7 \%)$ in the WWS determines its active effect on the phosphate regime of soils. In the process of mineralization, the degree of mobility of phosphates in the form of organic compounds increases, which is especially manifested in the aftereffect. The potassium content in sediments is much less, only $0.32 \%$, therefore, use of WWS practically does not affect the change in the availability of potassium in soils. The valuable properties of waste sludge are associated with the content of a large amount of organic matter in them.

Use of sewage sludge containing large amounts of heavy metals as one of the soil components undoubtedly leads to increase in the amount of these toxic elements in the soil as a whole. So, the content of heavy metals in soils is presented in following Table 2.

Table 2. Gross content of heavy metals in WWS-soils, $\mathrm{mg} / \mathrm{kg}$

\begin{tabular}{|c|c|c|c|c|c|c|c|c|}
\hline \multirow{2}{*}{$\begin{array}{c}\text { No } \\
\text { of } \\
\text { option }\end{array}$} & \multirow{2}{*}{ Option } & \multicolumn{7}{|c|}{ Heavy metals } \\
\cline { 4 - 10 } & & Cd & Co & Cu & Ni & Pb & Zn \\
\hline 1 & Control & a & 0.6 & 3.1 & 19.7 & 14.3 & 9.0 & 82.6 \\
& & b & 0.7 & 3.0 & 14.2 & 13.5 & 7.0 & 49.7 \\
\hline \multicolumn{7}{|c|}{ WWS: sawdust: peat } \\
\hline 2 & $0.5: 1: 1$ & a & 74.5 & 3.2 & 455.3 & 260.1 & 174.6 & 2693.0 \\
& & b & 60.2 & 2.7 & 411.0 & 237.2 & 147.5 & 1885.2 \\
\hline 3 & $0.5: 2: 1$ & a & 66.1 & 3.3 & 448.4 & 246.7 & 154.7 & 1747.7 \\
& & b & 88.7 & 3.7 & 547.3 & 300.0 & 215.8 & 2220.6 \\
\hline 4 & $0.5: 1: 2$ & a & 10.1 & 2.6 & 220.9 & 155.1 & 54.6 & 781.3 \\
& & b & 12.2 & 2.4 & 216.1 & 148.5 & 64.5 & 798.4 \\
\hline 5 & $1: 1: 1$ & a & 128.9 & 3.9 & 798.7 & 433.5 & 310.6 & 2448.3 \\
& & b & 130.8 & 3.1 & 785.7 & 412.9 & 297.3 & 2358.4 \\
\hline
\end{tabular}

It can be seen from several years of study that use of composts in any proportions increased the content of heavy metals in soils. The exception was the indicator of the content of cobalt, its concentration did not change relative to the control. Sewage sludge is 
characterized by a high zinc content, therefore, in options with use of WWS-soils, its gross content ranges from 71 to $2693 \mathrm{mg} / \mathrm{kg}$. The content of heavy metals of the first hazard class in composts from sewage sludge significantly exceeds their content in standard soil. The return of biomass to the soil-plant system has an ambiguous effect on the accumulation of toxicants in the soil.

One of the main indicators determining the suitability of precipitation for their use as fertilizer is a positive effect on the productivity of culture phytocenosis. Long-term observations indicate that at normal plant density, the yield of herbage according to the options of the experiment during the growing season varied from 6.9 to $13 \mathrm{~kg} / \mathrm{m}^{2}$ (Table 3 ). Introduction of organic waste in all options contributed to an increase in plant productivity in comparison with the control option. The maximum increase in biomass (156\% to the control) showed that for formation of a lawn culture, the best option is to apply compost in an equal ratio of WWS: sawdust: peat. At the same time, when the biomass was returned to the system, an increase in the proportion of silt in the compost from 0.5 to 1.0 had little effect on plant productivity.

Table 3. Total productivity of meadow fescue in 2019

\begin{tabular}{|c|c|c|c|c|}
\hline \multirow{3}{*}{$\begin{array}{c}\text { Opti } \\
\text { on } \\
\text { No. }\end{array}$} & \multirow{3}{*}{ Option } & \multicolumn{3}{|c|}{ Green mass yield } \\
\hline & & \multirow{2}{*}{$\begin{array}{c}\text { In total for } \\
\text { two mows, } \\
\mathrm{kg} / \mathrm{m}^{2}\end{array}$} & \multicolumn{2}{|c|}{ Difference with control $\left({ }^{+}-\right)$} \\
\hline & & & $\mathrm{kg} / \mathrm{m}^{2}$ & $\%$ \\
\hline \multicolumn{5}{|c|}{ Series "a" - return of biomass to the system } \\
\hline 1 & Control & 6.90 & & - \\
\hline \multicolumn{5}{|c|}{ WWS: sawdust: peat } \\
\hline 2 & $0.5: 1: 1$ & 11.67 & +4.77 & +69.13 \\
\hline 3 & $0.5: 2: 1$ & 13.02 & +6.12 & +88.70 \\
\hline 4 & $0.5: 1: 2$ & 7.92 & +1.02 & +14.78 \\
\hline 5 & 1: $1: 1$ & 6.93 & +0.03 & +0.43 \\
\hline \multicolumn{5}{|c|}{ Series "b" - alienation of biomass from the system } \\
\hline 1 & Control & 5.82 & - & - \\
\hline \multicolumn{5}{|c|}{ WWS: sawdust: peat } \\
\hline 2 & $0.5: 1: 1$ & 10.89 & +5.07 & +87.11 \\
\hline 3 & $0.5: 2: 1$ & 8.91 & +3.09 & +53.09 \\
\hline 4 & $0.5: 1: 2$ & 11.40 & +5.58 & +95.88 \\
\hline 5 & 1: $1: 1$ & 14.91 & +9.09 & +156.19 \\
\hline
\end{tabular}

Sewage sludge, like any organic fertilizers, has a significant and long-term aftereffect [1, $4,9]$. In a long-term lysimetric experiment, the largest yield in the second cut was provided by options with the ratios of fertilizing materials: 0.5: 2: 1 and 1: 1: 1 (Fig. 1.2). The biomass yield in these options in the first cut is significantly higher than the control and exceeds the results of the second cut of the control option by more than two times. It shall be noted that the aftereffect was more noticeable in series $b$, with the removal of the cut grass. In the option with the full dose of WWS (1: 1:1), the yield of green mass of the second cut was 2.5 times higher than the control, and exceeded the biomass of the first cut. 


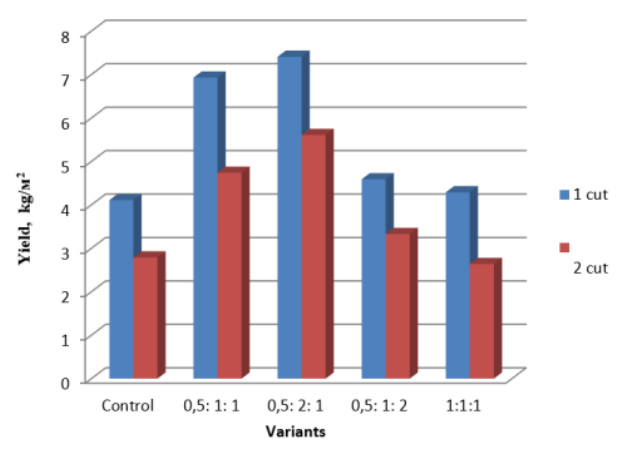

Fig. 1. The yield of fescue when returned to the lysimeter

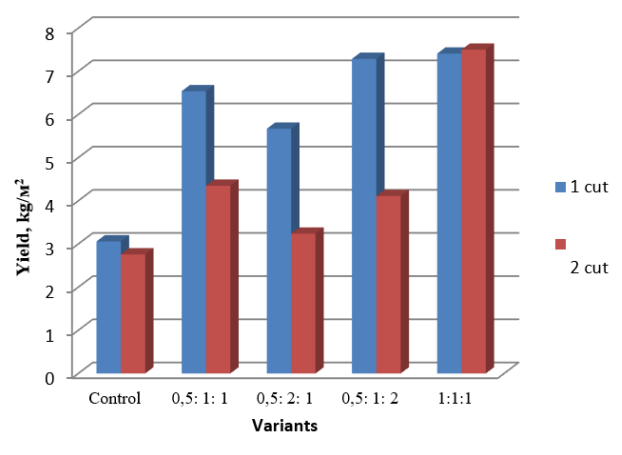

Fig. 2. Fescue yield when alienated from a lysimeter

The lawn maintenance regime largely determines the water-physical and acid-base properties of soils and grounds, as well as the balance of nutrients. All of the above is inevitably reflected in changes in the productivity of the phytocenosis. The higher efficiency of the mixture of fertilizing materials with the ratio of WWS: sawdust: peat - 0.5: 2: 1 in the series of options "a" is probably associated with the optimal $\mathrm{pH}$ value, as well as the physiological characteristics of meadow fescue [18] (Table 4).

Table 4. Comparison of the maintenance regimes for the lawn sown with meadow fescue in 2019

\begin{tabular}{|c|c|c|c|c|c|}
\hline \multirow[t]{2}{*}{$\begin{array}{l}\text { No } \\
\text { of } \\
\text { option }\end{array}$} & \multirow[t]{2}{*}{ Option } & \multirow[t]{2}{*}{$\begin{array}{l}\text { Series "a" - return } \\
\text { of biomass to the } \\
\text { "soil-plant" system }\end{array}$} & \multirow[t]{2}{*}{$\begin{array}{l}\text { Series "b" - } \\
\text { alienation of over- } \\
\text { terrestrial biomass }\end{array}$} & \multicolumn{2}{|c|}{$\begin{array}{c}\text { Mode "a" in } \\
\text { comparison } \\
\text { with mode "b" }\end{array}$} \\
\hline & & & & $\mathrm{kg} / \mathrm{m}^{2}$ & $\%$ \\
\hline \multicolumn{6}{|c|}{ Productivity of green mass, $\mathrm{kg} / \mathrm{m}^{2}$} \\
\hline 1 & Control & 6.90 & 5.82 & +1.08 & +15.65 \\
\hline \multicolumn{6}{|c|}{ WWS: sawdust: peat } \\
\hline 2 & $0.5: 1: 1$ & 11.67 & 10.89 & +0.78 & +6.68 \\
\hline 3 & $0.5: 2: 1$ & 13.02 & 8.91 & +4.11 & +31.57 \\
\hline 4 & $0.5: 1: 2$ & 7.92 & 11.40 & -3.48 & -43.94 \\
\hline 5 & 1: $1: 1$ & 6.93 & 14.91 & -7.98 & -115.15 \\
\hline
\end{tabular}

\section{Conclusions}

As a result of the study carried out, the following conclusions can be drawn up:

1. Soils based on sewage sludge contain plant nutrients and are suitable for use as fertilizing materials in green building and for creating grass stands.

2. Use of sewage sludge as one of the soil components leads to an increase in the amount of heavy metals in the soil as a whole. The zinc content is especially high (up to $2693 \mathrm{mg} / \mathrm{kg}$ ). Excessive levels of cadmium and lead in prepared soils can be considered environmentally hazardous.

3. The high efficiency of WWS and composts in the cultivation of cereal grasses under the conditions of vegetative lysimetric experiments was noted. The maximum yield increase, at the level of $156 \%$, was obtained in the variant with the introduction of compost in an equal ratio of WWS: sawdust: peat. At the same time, the aftereffect was more noticeable in series " $b$ ", with the alienation of the aboveground biomass. 


\section{References}

1. V. I. Titova, I.A. Pitina, M. V. Dabakhov, International Agricultural Journal, 62, 24-27 (2019)

2. A. Burges, I. Alkorta, L. Epelde, C. Garbisu, International Journal of Phytoremediation, 20, 384-397 (2018)

3. S. Gintaras, K. Danute, A. Jurate, Zemdirbyste-Agriculture, 106, 213-218 (2019)

4. L. D. Varlamova, I. D. Korolenko, Agrochemical Bulletin, 2, 17-20 (2017)

5. A.Lavrishchev, A.Litvinovich, V.Bure, O.Pavlova, E. Saljnikov, Biological communications, 3, 163-173 (2018)

6. V.N.Efimov, V.P.Tsarenko, Eurasian soil science, 2, 57-67 (1993)

7. N. A. Zaitseva and A. N. Pyrsikova, International Research Journal, 3-1, 104-105 (2015)

8. N. T. Chebotarev, N. D. Naydenov, A. A. Yudin, Science. Thought: electronic periodical, 6, 31-36 (2016)

9. I. V. Elshaeva, E. V. Voropaeva, A. S. Pinaeva, The International Scientific and Practical Conference BAICSEM 2020 (2020)

10. V. I.Titova, I. A.Pitina, E. U.Sudakov, International agricultural journal, 62(4), 111 120 (2019)

11. V. I. Smetanin, V. N. Zemskov, Scientific Life, 1, 38 (2015)

12. A. Kwarciak-Kozłowska, Industrial and Municipal Sludge, 337-360 (2019)

13. R. F. Baybekov, G. E. Merzlaya, O. A. Vlasova, Agriculture, 34-36 ( 2015)

14. A. Grobelak, M. Jaskulak, Sludge multifunctions in a phytobiome - Forest and plantation application including microbial aspects, Industrial and Municipal Sludge (United Kingdom, Oxford : Butterworth-Heinemann), 323-336 (2019)

15. L.V. Bryndina O. V. Baklanova, Forestry Engineering Journal, 9, 23-30 (2019)

16. GOST R 54651-2011, Organic fertilizers on the basis of sewage sludge

17. SanPiN 2.1.7.573-96, Soil, cleaning of inhabited areas, domestic and industrial waste, sanitary protection of soil

18. V. F. Drichko, M. A.Efremova, A. A.Izosimova, Radiation biology. Radioecol-ogy, 2, 166-171 (2009) 